\title{
Sistem Pendukung Keputusan Penerimaan Siswa Baru Menggunakan Proses Hirarki Analitik Dan Metode Pembobotan Aditif Sederhana
}

\author{
Arden Simeru $^{1 *}$, Ambiyar ${ }^{2}$ dan Wakhinuddin ${ }^{2}$ \\ ${ }^{1}$ Sekolah Tinggi Teknologi Pekanbaru \\ ${ }^{2}$ Program Pascasarjana, Fakultas Teknik, Universitas Negeri Padang \\ *e-mail : asimeru@gmail.com
}

\begin{abstract}
Abstrak- Penelitian ini dilatarbelakangi oleh penerimaan siswa baru pada SMKN 4 Pekanbaru masih menggunakan Microsoft Excel dan mengunakan metode AHP dan metode SAW. Studi ini bertujuann untuk memudahkan sesorang dalam melakukan penerimaan siswa baru pada setiap instansi atau sekolah masingmasing.Masalah tersebut juga berdampak pada siswa yang tidak diterima. Tujuan peneliti adalah untuk memudahkan panitia penerimaan siswa baru di SMKN 4 Pekanbaru. Metode penelitian menggunakan metode AHP yang berfungsi untuk menghitung kriteria pembobotan terkait dengan akademis dan metode SAW digunakan untuk menghitung pembobotan serta kriteria dari beberapa kuesioner. Dari penelitian ini ditentukan adanya beberapa siswa dengan nilai yang diperoleh dalam penerimaan siswa baru yaitu nilai tertinggi yaitu 9,85 dan terendah 6,23 .
\end{abstract}

Kata Kunci : Pendukung Keputusan, Proses Hirarki Analitik dan Pembobotan Sederhana

\begin{abstract}
This research is motivated by the admission of new students at SMK 4 Pekanbaru still using Microsoft Excel and using the AHP method and the SAW method. This study aims to facilitate someone in accepting new students in each agency or school. The problem also affects students who are not accepted. The aim of the researcher is to facilitate the committee for admission of new students at SMK 4 Pekanbaru. The research method uses the AHP method which functions to calculate the academic weighting criteria and the SAW method is used to calculate the weighting as well as the criteria of several questionnaires. From this study, it was determined that there were some students with grades obtained in the admission of new students, namely the highest value of 9.85 and the lowest of 6.23 .
\end{abstract}

Keywords : Decision Support, Analytic Hierarchy Process and Simple Weighting

This is an open access article distributed under the Creative Commons 4.0 Attribution License

\section{Pendahuluan}

SMK adalah merupakan salah satu instansi sekolah tingkat SLTA yang dalam pengelolaan penerimaan siswa baru masih menggunakan metode pembobotan aditif sederhana. Dengan metode tersebut dirasa belum memenuhi standarisasi yang ditetapkan pemerintah sehingga mengurangi kemampuan tingkat kerja dalam administrasi penerimaan siswa baru yang membantu bagi panitia penerimaan siswa baru dalam melakukan pendataan dan menghasilkan laporan yang valid dan akurat. Diharapkan dengan adanya Sistem ini dapat membantu memudahkan lembaga tersebut dalam melakukan pendataan kepada calon peserta didik barunya.

Sekarang ini Kebutuhan dan pemulihan dunia kerja pada era industri 4.0 menuntut tenaga kerja kompetitif. Oleh karena itu dunia pendidikan melalui lembaga pendidikan harus dapat membeli manusia memiliki karakter yang kuat, kompeten, kreatif, inovatif, dan kompeten di bidang technopreunership juga peka terhadap Lingkungan lokal juga global, terutama bagi siswa SMK [8].

Pada zaman yang terus berkembang dari tahun ke tahun, dunia pendidikan merupakan suatu penerus bagi anak-anak bangsa indonesia untuk meraih masa depan yang cerah [6]. Di dalam sebuah lembaga pendidikan terjadi beraneka ragam 
kegiatan, salah satunya adalah kegiatan penerimaan calon siswa baru. Pihak lembaga pendidikan memerlukan sistem pelayanan komputerisasi dan proses pengolahan yang dapat menyajikan informasi yang cepat dan tepat serta akurat sesuai dengan peraturan di setiap instansi. Untuk itu SMKN 4 Pekanbaru perlu untuk meningkatkan pelayanan yang baik dalam seleksi penerimaan calon siswa baru, di instansi memerlukan sistem komputerisasi membuat palayanan terhadap calon siswa agar tidak lambat dan kurang optimal serta memudahkan dalam menggunakannya.

Sekolah kejuruan dimaksudkan untuk mempersiapkan penerimaan siswa baru agar siswa baru bisa melanjutkan jenjang Pendidikan ketingkan yang lebih tinggi.agar dapat berkembang lebih baik dan memiliki peluang dikemudian hari.

Proses seleksi untuk penerimaan siswa baru di SMKN 4 Pekanbaru didasarkan pada kriteria yang telah ditetapkan dari suatu instansi masing-masing SMK. Baik karena beberapa metode yang digunakan masih banyak kesalahan dalam menginput data terutama untuk calon siswa baru SMK Negeri 4 Pekanbaru yang akan mendaftar di instansi tersebut dengan jurusan yang berbedabeda.

Penghitungan hasil penilaian di SMK Negeri 4 Pekanbaru, yaitu: nilai bobot yang diberikan dalam masing-masing kriteria ini bertujuan untuk membantu proses memasuki ujian tes tertulis dan wawancara serta pendaftaran ulang disetiap instansi masing-masing untuk menghasilkan peringkat terbaik, sehingga meminimalkan kesalahan disetiap instansi dalam menggunakan metode tersebut.

Singkatnya, jelas terlihat lulusan SMK menghadapi tantangan yang dapat diringkas sebagai berikut; Kesenjangan keterampilan (ketidakcocokan atau tautan dan kecocokan) antara SMK kurikulum dan kebutuhan industri, kurangnya pengalaman lapangan oleh guru yang mengajar di SMK, fasilitas pembelajaran yang tidak memadai terutama peralatan untuk praktik sekolah dan kaku kompetisi. Karena itu, agar SMK meningkat kompetensi dan kualitas lulusannya, SMK / VHS harus membangun dan menerapkan hubungan kerja sama dengan Industri. Diyakini itu kepala sekolah lulusan SMK di dunia kerja nyata yang meningkatkan kualitas kejuruan tinggi sekolah [2].

Ada beberapa sarana untuk mendukung daya tarik masayrakat terhadap Sekolah Menangah Kejuruan, Pertama, bagaimana industri mendukung kejuruan sekolah menengah dalam hal
Infrastruktur dan Fasilitas sebagai tautan ke kerja sama?, Kedua, bagaimana industrinya mendukung sekolah dalam meningkatkan kompetensi guru dan keterampilan siswa dalam setiap bidang IT sebagai tautan ke kerja sama?, Ketiga, bagaimana apakah sekolah menengah kejuruan mendapat dukungan industri hal meningkatkan kompetensi dan keterampilan Siswa di bidang IT sebagai tautan kerja sama ?, dan Keempat, apa bentuk kerja sama ada antara sekolah ini dengan industri di departemen teknologi informasi dan apa proses kerjasamanya?

Hal ini karena di SMK ada (1) kesenjangan keterampilan karena ketidakcocokan di Program dan kebutuhan masing-masing, (2) kelemahan dalam menguasai bidang raktikum, (3) guru yang tidak kompeten dengan pelatihan dan pengalaman pembelajaran yang digunakan, (4) sejumlah besar lulusan SMK yang mengarah ke kompetisi yang tinggi di antara lulusan, dan (5) pembelajaran yang tidak memadai sesuai dengan bidang yang di ajarkan di sekolah kejuruan (SMK) dan (6) arus informasi terbatas kepada lulusan SMK tentang penerimaan calon siswa baru di SMK Negeri 4 Pekanbaru. Karena tantangan pendidikan inilah umumnya terkait dengan peralatan dan fasilitas, sedikit praktik, dan lingkungan belajar yang tidak sesuai dengan dunia kerja mengurangi kualitas dan kompetensi lulusan SMK [1].

Sekolah Menengah Kejuruan adalah salah satu instansi sekolah tingkat SLTA yang dalam penerimaan calon siswa baru dengan menggunakan metode AHP dan SAW. Dengan metode tersebut dirasa belum memenuhi standarisasi yang ditetapkan pemerintah sehingga mengurangi prestasi instansi tersebut pada saat akreditasi. Sistem informasi ini bertujuan untuk memudahkan dalam administrasi penerimaan calon siswa baru yang membantu bagi panitia penerimaan siswa baru di setiap instansi tersebut [15].

Manfaat dari sistem ini antara lain mudah dalam melakukan pendaftaran dan menghasilkan laporan yang valid dan lebih akurat. Metode yang digunakan adalah metode AHP dan SAW. Diharapkan dengan adanya sistem ini dapat membantu memudahkan lembaga tersebut dalam melakukan penerimaan calon peserta didik barunya.

Dari keuntungan menggunakan AHP sebagai alat analisis adalah: 1) Memudahkan setiap instansi dalam penerimaan calon siwa baru agar mudah dimengerti, tetapi untuk beragam diskusi yang tidak terstruktur. 2) Memudahkan dalam pengentrian data siswa pada setiap pendaftaran calon siswa baru di setiap instansi masing-masing. 3) Dapat saling bergantung dengan elemen-elemen 
yang bersangkutan dalam sistem dan tidak memaksakan pemikiran linier. 4) Demudahkan dalam suatu proses yang di lakukan oleh instansi untuk memilah-milah elemen-elemen suatu sistem dalam berbagai tingkat berlainan dan mengelompokkan yang tidak terkait dalam setiap tingkat pendidikan. 5) Memberikan nilai ukur yang mempunyai skala yang dapat terwujud untuk mendapatkan prioritas baik disetiap instansi. 6) AHP melacak data yang yang ketahuan sama saat digunakan dalam menentukan berbagai prioritas. AHP menuntun ke semua taksiran tentang apa saja setiap alternative yang dilakukan dalam penerimaan calon siswa baru. 7) AHP pertimbangkan prioritas-prioritas relatif dari berbagai faktor sistem dan memungkinkan orang memilih jalan alternatif terbaik sesuai tujuantujuan mereka. 8) AHP tidak memaksakan konsensus tetapi mensintesis suatu hasil mewakili dari yang berbedabeda disetiap instansi. 9) AHP memungkinan orang memperhalus resolusi mereka agar tertarik memasuki instansi yang di pilih pada saat penerimaan calon siswa baru di SMK Negeri 4 Pekanbaru [12]; [13].

Kelebihan dari model Simple Additive Weighting (SAW) dibandingkan dengan model pengambilan keputusan yang lain terletak pada kemampuannya untuk melakukan penilaian secara lebih tepat karena didasarkan pada nilai kriteria dan bobot preferensi yang sudah ditentukan, selain itu SAW juga dapat menyeleksi alternatif terbaik dari sejumlah alternatif yang ada karena adanya proses perankingan setelah menentukan nilai bobot untuk setiap atribut dapat ditentuan lebih mudah dan cepat dengan menggunakan metode SAW tersebut.

Pemerintah Indonesia mengakui hal itu Pendidikan Teknik dan Pendidikan Kejuruan (SMK) sangat berperan dalam pengembangan dunia pendidikan yang lebih unggul dengan menciptakan tenaga kerja yang terampil, meningkatkan produktivitas industri dan meningkatkan kualitas hidup. Itu Pemerintah Indonesia melalui Kementerian Pendidikan dan Kebudayaan adalah upaya untuk mencapai transisi lengkap dari rasio pendaftaran siswa sekolah menengah umum (SMA) ke sekolah menengah kejuruan (SMK) mulai pukul 70:30 hingga 15:00 secara tersirat menyatakan bahwa saat ini pemerintah lebih menghargai pendidikan kejuruan untuk umum pendidikan dengan tujuan daya tarik SMK Negeri 4 Pekanbaru dalam proses penerimaan siswa baru [3]; [4].

Tujuan dari penelitian di atas adalah pembuatan untuk mempermudah sekolah dalam membuat keputusan seleksi bagi calon siswa baru berdasarkan bakat, minat, dan kemampuan mereka dalam memilih bidang keahlian yang diminati.

Penerimaan siswa baru di SMKN 4 Pekanbaru sudah diterapkan mulai tahun 2014 dan digunakan untuk penerimaan siswa baru SMKN 4 Pekanbaru. Minat untuk masuk ke SMKN 4 Pekanbaru cenderung lebih banyak dibandingkan dengan SMA. Sehingga peneliti menggunakan metode pembobotan aditif sederhana.

Metode yang digunakan di dalam penelitian penulis yakni untuk menentukan nilai siswa untuk masuk ke SMK Negeri 4 Pekanbaru melalui seleksi calon siswa baru, penguman administrasi, dan pendaftaran ulang siswa baru bagi yang telah di tentukan diterima, dan peminatan jurusan yang baik sesuai dengan kriteria yang ditentukan oleh pihak sekolah SMK Negeri 4 Pekanbaru.

Selama ini SMK Negeri 4 Pekanbaru masih belum maksimalnya bagi penerimaan calon siswa baru karena siswa yang melamar di setiap instansi lain masih banyak, maka untuk itu perlu ditingkatkan lagi minat siswa untuk masuk ke SMK Negeri 4 Pekanbaru dengan menggunakan metode yang sesuai di setiap instansi masingmasing agar bisa berkembang lebih baik untuk tahap selanjutnya.

Perkembangan teknologi informasi yang sangat pesat dapat memenuhi berbagai aktifitas dan kebutuhan manusia, komputer mampu memberikan efektifitas kehidupan yang baik bagi manusia, selain itu dengan adanya komputer seseorang mampu menciptakan sesuatu yang bermanfaat. Teknologi sekarang ini yaitu teknologi internet yang mempunyai ke istimewaan untuk mengetahui informasi di belahan dunia lain tanpa terhalang oleh adanya jarak, waktu dan tempat. Dengan pertimbangan diatas maka diperlukan sesuatu yang dapat menyelesaikan kendala, khususnya dalam hal pelaksanaan pendaftaran calon siswa baru di SMK Negeri 4 Pekanbaru.

Penerimaan siswa baru yaitu kegiatan suatu instansi pendidikan dimana setiap sekolah melakukan penerimaan siswa baru guna meningkatkan minat siswa untuk mendaftar ke instansi yang dituju. Siswa baru yang lolos harus memenuhi syarat yang ditentukan oleh instansi yang bersangkutan dengan setiap instansi masingmasing sekolah [14].

Penerimaan siswa baru awalnya dilakukan secara bertahap yang menyebabkan adanya kesalahan dalam penyimpanan data yang akan 
diproses, sehingga memakan waktu yang sangat lama [19]. Sistem informasi yang dibangun berfungsi untuk membantu para siswa baru untuk menentukan sekolah yang diinginkan dan berfungsi sebagai tolok ukur dalam proses diterima atau tidaknya siswa baru dalam pendaftaran siswa baru [20].

Metode AHP berfungsi untuk menghitung kriteria pembobotan terkait dengan akademisi, termasuk layanan, penelitian, bimbingan dan pengajaran, metode SAW digunakan untuk menghitung pembobotan serta kriteria dari beberapa kuesioner dari kolega, siswa, dosen dan pengawas [7].

Berdasarkan penelitian tentang penerimaan siswa baru di SMK Negeri 4 Pekanbaru dapat disimpulkan bahwa penelitian yang dilakukan berhasil melakukan peringkat alternatif dari bobot penilaian kinerja dosen [13]. Penghitungan beberapa kriteria dari siswa, pimpinan, sejawat, dan dosen menggunakan metode SAW untuk memberikan hasil yang lebih adil dan obyektif untuk setiap kinerja dosen. Hasil SAW diperoleh, menjadi kriteria yang dikombinasikan dengan perhitungan akademik internal termasuk kriteria untuk layanan, penelitian, bimbingan dan pengajaran menggunakan metode AHP dan hasilnya menjadi keputusan akhir [13].

Pemrosesan kriteria yang ada di sekolah digunakan untuk menentukan penerimaan siswa dapat membuat keputusan yang tepat dalam menentukan penerimaan siswa baru, dan akan meminimalkan kesalahan dalam pengambilan keputusan [13]. Metode perhitungan menggunakan nilai bobot untuk proses pemeringkatan, dan untuk menentukan bobot masing-masing kriteria yang ditentukan oleh sekolah. Pengujian sistem sesuai dan berjalan seperti yang diharapkan, ini dapat ditunjukkan pada hasil tes respon dan status sesuai dengan masing-masing tes dengan baik. menguji kesesuaian proses, fungsionalitas, menguji kesesuaian input dengan output, pengujian kelayakan sistem, bersama dengan uji algoritma.

Pengambilan keputusan dalam memilih siswa baru menggunakan metode SAW untuk memudahkan instansi dalam penerimaan siswa baru ini akan memberikan saran sebagai bahan pertimbangan dalam memutuskan siswa mana yang memenuhi syarat untuk masuk sekolah SMK Negeri 4 Pekanbaru [10].

Melakukan penelitian tentang pemilihan jurusan dengan Fuzzy Multiple Pengambilan Keputusan Atribut dengan metode SAW menghasilkan kesimpulan bahwa semakin banyak sampel yang digunakan, tingkat validitas yang diperoleh cenderung meningkat, dan hasil penelitian ini merupakan alternatif yang memiliki nilai bobot disetiap masing-masing siswa yang terbaik di antara alternatif yang ada. Hasil penelitian percobaan yang dilakukan pada pemilihan jurusan di pendidikan tinggi dengan menggunakan AHP menunjukkan bahwa rekomendasi departemen disesuaikan dengan kemampuan, minat, dan preferensi siswa, serta preferensi pengguna kriteria dan subkriteria yang digunakan [11].

\section{METODE}

Penelitian ini bertujuan untuk memudahkan dan merekomendasi calon siswa baru dalam menentukan jurusan masing-masing instansi yaitu mengindentfikasi masalah, studi literatur, Analisa masalah dan hasil penelitian, seperti gambar:

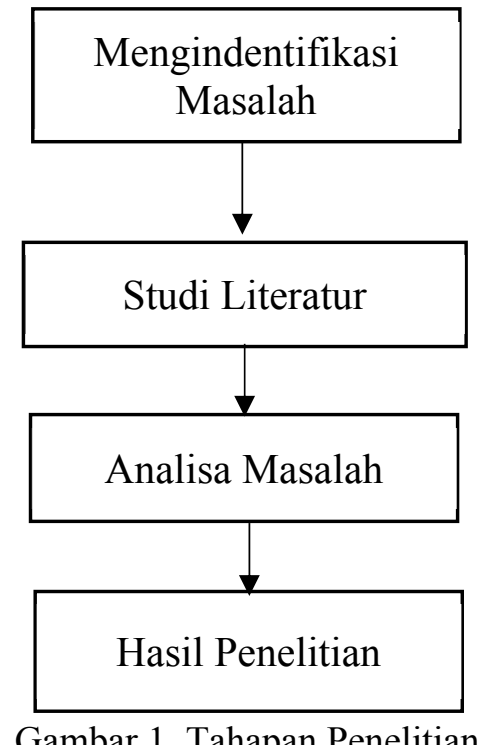

\section{A. Deskripsi penelitian}

Deskripsi penelitiannya adalah sebagai berikut.

a. Mengidentifikasi masalah merupakan tahapan menentukan agar dapat menentukan proses penerimaan siswa baru pada instansi masing-masing sekolah.

b. Pada Tahap kedua ini melakukan penerimaan siswa baru dari sekolah lain agar bisa masuk keinstansi yang dipilih.

c. Analisa masalah melakukan untuk menentukan permasalahan yang dialami pada saat seleksi calon siswa baru di setiap instansi.

d. Hasil Penelitian dilakukan berdasarkan hasil yang diperoleh dari tahap analisa masalah. Dalam penerimaan siswa baru di SMKN 4 Pekanbaru. 


\section{B. Metode Pengumpulan Data}

a. Observasi Penulis mengumpulkan data dari SMKN 4 yang berada di Pekanbaru dan mencari informasi melalui pengamatan secara langsung pada SMKN 4 Pekanbaru.

b. Wawancara Penulis mengumpulkan data dari sekolah yang berada di SMKN 4 Pekanbaru yang disampaikan dengan lisan dan melalui tatap muka dengan guru yang bersangkutan.

c. Kuesioner Penulis juga mengumpulkan data informasi melalui kuesioner, yaitu dengan cara membuat kuesioner yang berisikan tentang perbandingan dalam penerimaan siswa baru pada SMKN 4 Pekanbaru.

Pihak yang berhubungan dengan penerimaan siswa baru pada SMKN 4 Pekanbaru seperti calon siswa baru, untuk menentukan siswa yang diterima. Jadi jumlah keseluruhan populasi yang penulis ambil dari penelitian ini adalah 50 orang

\section{HASIL DAN PEMBAHASAN}

Penelitian ini adalah kualitatif dengan pendekatan deskriptif yang dimaksudkan untuk memperoleh pengetahuan lebih dari persepsi responden penelitian tentang gagasan SMKkerjasama industri [9]. Penelitian populasi adalah
10 orang siswa di SMK Negeri 4 Pekanbaru adalah subjek penelitian. Acak sederhana Metode pengambilan sampel digunakan dalam pemilihan sampel [5]; [15]; [16]; [17]. Dengan sampel ukuran 25 responden dengan 10 peserta dari masingmasing SMK karena sampelnya kurang dari 50 orang.

Tabel 1. Kriteria dan deskripsi

\begin{tabular}{|c|c|c|}
\hline Alternatif & Criteria & Descrimination \\
\hline A1 & C1 & Tes Nasional \\
\hline A2 & C2 & Tes Akademik \\
\hline A3 & C3 & Tes Psikotes \\
\hline A4 & C4 & $\begin{array}{c}\text { Tes } \\
\text { Wawancara }\end{array}$ \\
\hline
\end{tabular}

Masing-masing data tersebut ditentukan menggunakan metode AHP. Yaitu dengan melakukan tes Nasional, tes akademik, Tes Psikotes, dan tes Wawancara untuk memasuki setiap instansi yang di pilih oleh calon siswa baru di SMK Negeri 4 Pekanbaru guna untuk melanjutkan pendidikan di masing-masing setiap instansi dengan menggunakan metode AHP dan SAW agar memudahkan setiap instasi saat melakukan seleksi perimaan siswa baru. Untuk menentukan kriteria setiap siswa [12].

Tabel 2. Kriteria dan Perbandingan Matrik

\begin{tabular}{|c|c|c|c|c|c|c|}
\hline \multirow[t]{2}{*}{ Alternatif } & \multirow{2}{*}{ Nama Siswa } & \multicolumn{4}{|c|}{ Kriteria } & \multirow[t]{2}{*}{ Hasil } \\
\hline & & $\mathrm{C1}$ & $\mathrm{C2}$ & $\mathrm{C3}$ & $\mathbf{C 4}$ & \\
\hline A1 & Hendri & 0,40 & 5,31 & 2,33 & 1,80 & 9,85 \\
\hline A2 & Nadia & 6,25 & 1,02 & 0,53 & 0,78 & 8,58 \\
\hline $\mathbf{A 3}$ & Iqbal & 5,10 & 2,31 & 0,31 & 0,74 & 8,46 \\
\hline A4 & Nery & 5,29 & 1,29 & 0,55 & 0,88 & 8,01 \\
\hline A5 & Putri & 1,40 & 0,15 & 3,31 & 3,05 & 7,91 \\
\hline A6 & Alex & 6,25 & 1,02 & 0,23 & 0,28 & 7,78 \\
\hline A7 & Aqila & 6,15 & 1,05 & 0,22 & 0,23 & 7,65 \\
\hline A8 & Nadine & 1,24 & 0,31 & 3,31 & 2,74 & 7,61 \\
\hline A9 & Acha & 2,40 & 0,15 & 2,31 & 2,05 & 6,91 \\
\hline A10 & Alya & 3,25 & 2,02 & 0,18 & 0,78 & 6,23 \\
\hline
\end{tabular}


Tabel 3. Hasil Perangkingan

\begin{tabular}{|c|c|c|c|c|c|c|c|}
\hline \multirow[t]{2}{*}{ Alternatif } & \multirow[t]{2}{*}{ Nama Siswa } & \multicolumn{4}{|c|}{ Kriteria } & \multirow[t]{2}{*}{ Hasil } & \multirow[t]{2}{*}{ Kesimpulan } \\
\hline & & $\mathrm{C} 1$ & $\mathrm{C} 2$ & $\mathrm{C3}$ & $\mathrm{C} 4$ & & \\
\hline A1 & Hendri & 0,40 & 5,31 & 2,33 & 1,80 & 9,85 & Diterima \\
\hline A2 & Nadia & 6,25 & 1,02 & 0,53 & 0,78 & 8,58 & Diterima \\
\hline A3 & Iqbal & 5,10 & 2,31 & 0,31 & 0,74 & 8,46 & Diterima \\
\hline A4 & Nery & 5,29 & 1,29 & 0,55 & 0,88 & 8,01 & Diterima \\
\hline A5 & Putri & 1,40 & 0,15 & 3,31 & 3,05 & 7,91 & Diterima \\
\hline A6 & Alex & 6,25 & 1,02 & 0,23 & 0,28 & 7,78 & Diterima \\
\hline A7 & Aqila & 6,15 & 1,05 & 0,22 & 0,23 & 7,65 & Diterima \\
\hline A8 & Nadine & 1,24 & 0,31 & 3,31 & 2,74 & 7,61 & Diterima \\
\hline A9 & Acha & 2,40 & 0,15 & 2,31 & 2,05 & 6,91 & Cadangan \\
\hline A10 & Alya & 3,25 & 2,02 & 0,18 & 0,78 & 6,23 & Cadangan \\
\hline
\end{tabular}

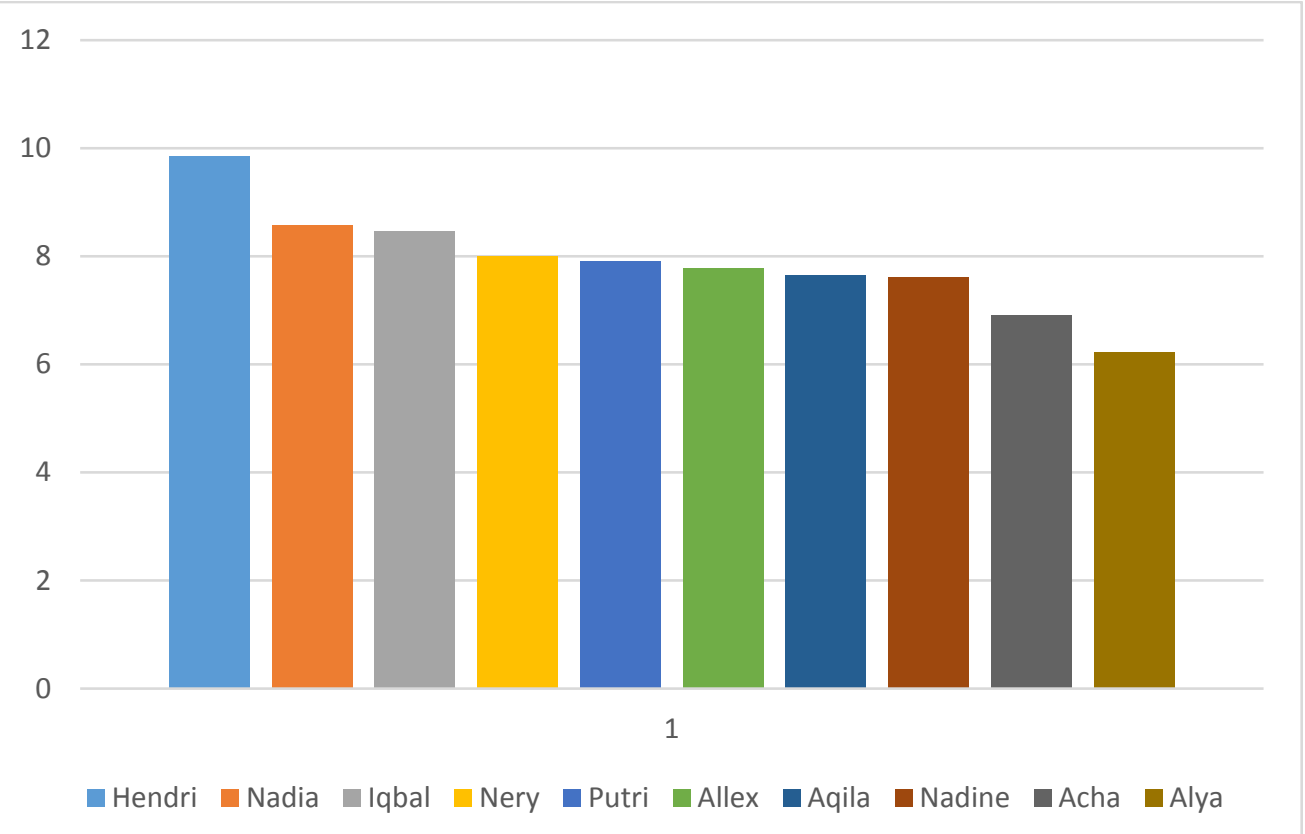

Gambar 2. Grafik Perangkingan

Berdasarkan Tabel 2, maka hasil nilai yang diperoleh dari seleksi penerimaan siswa baru adalah Hendri $=9,85$, Nadia $=8,58$, Iqbal $=8,46$, Nery $=8,01$, Putri $=7,91$, Alex $=7,78$, Aqila $=7,65$, Nadine $=7,61$, Acha, 9,91, dan Alya $=6,23$. Proses penentuan penerimaan siswa baru.

Berdasarkan Tabel 3, nilai awal yang akan digunakan dalam hasil perengkingan yang digunakan untuk penerimaan siswa baru adalah Hendri $=$ diterima, Nadia $=$ diterima, Iqbal $=$ diterima, Nery $=$ diterima, Putri $=$ diterima, $A l e x=$ diterima, Aqila $=$ diterima, Nadine $=$ diterima, Acha, Cadangan, dan Alya $=$ Cadangan .

Dari perangkingan dari grafik gambar 2 dapat menghasilkan peringkat tertinggi, Hendri pertama dengan nilai total 9,85, Nadia kedua dengan nilai 8,58 , Iqbal ketiga dengan nilai 8,46 , Nery keempat dengan nilai 8,01, Putri kelima dengan nilai 7,91, Alex keenam dengan nilai 7,78, Aqila ketujuh gengan nilai 7,65, Nadine kedelapan dengan nilai 7,61, Acha kesembilan dengan nilai 6,91 dan Alya kesepuluh dengan nilai 6,23 . 


\section{KESIMPULAN}

Berdasarkan kesimpulan dari metode tersebut, terdapat siswa yang memperoleh nilai tertingi dan terendah serta siswa cadangan yang terdapat pada setiap instansi dan kemampuan yang sesuai dengan bobot masing-masing.

Untuk panitia penerimaan siswa baru pada SMKN 4 Pekanbaru disarankan agar menerapkan metode AHP dan SAW ini dalam penerimaan calon siswa baru agar lebih efektif dan efesien, untuk peneliti sistem pendukung keputusan penerimaan siswa baru selanjutnya agar menambahkan penentuan kelas untuk siswa agar siswa tidak ragu atau kebingungan setelah menjadi siswa SMKN 4 Pekanbaru yang menggunakan metode AHP dan SAW.

\section{DAfTAR PUSTAKa}

[1] Apindo: Kualitas Lulusan SMK Belum Penuhi Kebutuhan Industri. (2017, 7 November). Republika. co.id. Diunduh dari https://republika.co.id/

berita/ekonomi/makro/17/11/07/oz18yx382apindokualitas-lulusan-smk-belumpenuhikebutuhan-industri.

[2] Azizah, Murniati, AR., Khairuddin. (2015). Strategi Kerjasama Sekolah Dengan Dunia Usaha Dan Dunia Industri (Du/Di) Dalam Meningkatkan Kompetensi Lulusan Pada SMK Negeri 3 Banda Aceh. Jurnal Administrasi Pendidikan: Program Pascasarjana Unsyiah, 3(2), 148-158.

[3] BNSP. (2015). Kualitas Tenaga Lulusan SMK Belum Sesuai yang Diharapkan Industri. Retrieved from http:// www.beritasatu.com/pendidikan/312762bnspkualitas-tenaga-lulusan-smk-belumsesuai-yangdiharapkan-industri.html.

[4] BNSP. (2015). Quality of SMK Graduates is Below Industry's Expectation. Retrieved from www.acdp-indonesia. org/.../bnsp-quality-ofsmk-graduates-is-belowindustrys-expect.

[5] Creswell, J.W. (2013). Research design: Qualitative, quantitative, and mixed methods approaches. Sage publications.

[6] Fitria, N. (2009), Prinsip Dasar dan Aplikasi Penulisan Laporan Pendahuluan dan Strategi Pelaksanaan Tindakan Keperawatan. Jakarta : Salemba.

[7] Handayani D Hakim F dan Solechan A, 2014, Pemilihan Sistem Pendukung Keputusan Fuzzy Departemen Pembuatan Keputusan Atribut Berganda.

[8] Haryono, Siswoyo. 2017. Metode SEM Untuk Penelitian Manajemen Dengan ... Neuhofer $e t$ al. 2015. IFIP International Federation for Information Processing, 280: 8.

[9] Helmy, A. (2014). VET Training and Industry Partnerships: a Study in East Java, Indonesia (Doctoral dissertation, Victoria University).

[10] Iqbal M D Sutarman dan Wulandari S, 2017 Sistem Pendukung Keputusan untuk Menerima Baru Siswa dengan Metode SAW di Sekolah Kejuruan Kusuma Bangsa 7, 2.

[11] Khuntari D dan Ferdiana R, 2015, Teknik yang Direkomendasikan untuk Pemilihan Departemen dengan Pendekatan Preferensi Pengguna dan Proses Hirarki Analitik, Seminar Nasional tentang Teknologi Informasi dan Multimedia.

[12] Putra P A Wirawan I M dan Sunarya I M, 2016, Pengembangan Sistem Pendukung Keputusan untuk Penerimaan Siswa Baru di SMA 1 Seririt dengan Metode SAW dan Metode AHP, Kumpulan Artikel Pendidikan Pendidikan Teknik Informatika (Karmapati) 5, 1.

[13] Putra S A Hidayat N dan Muflikhah L, 2017, Rekomendasi tentang Pemilihan Properti di Jakarta Kota Malang dengan Jurnal Metode Teknologi Informasi AHP dan SAW Pengembangan dan Ilmu Komputer

[14] Ramadhani, Nurul Azizah Yaoma. 2013. Pembangunan Sistem Informasi Penerimaan Siswa Baru Di Sekolah Menengah Kejuruan Al-Irsyad Tegal. Indonesian Jurnal on Computer Science - Speed (IJCSS) 15 Vol 10 No 1 ISSN:1979-9330.

[15] Santoso, (2010). Statistik Parametrik, Konsep dan Aplikasi dengan SPSS.

[16] Sugiyono. (2011). Educational Research Methods. Bandung: Alfabeta.

[17] Sugiyono. (2012). Statistics for Research. Bandung: Alfabeta.

[18] Sulistianingsih., Purnama, Eka Bambang., \& Sukadi. 2012. Sistem Informasi Penerimaan Siswa Baru Berbasis Web Pada Sekolah Menengah Kejuruan (SMK) PGRI Donorojo. Indonesian Jurnal on Computer Science Speed (IJCSS) 13 FTI UNSA Vol 9 No 3 ISSN:1979-9330.

[19] Sulistianingsih., Purnama, Eka Bambang., \& Sukadi. 2012. Sistem Informasi Penerimaan Siswa Baru Berbasis Web Pada Sekolah Menengah Kejuruan (SMK) PGRI Donorojo. Indonesian Jurnal on Computer Science Speed (IJCSS) 13 FTI UNSA Vol 9 No 3 ISSN:1979-9330.

[20]Zurati. 2012. Perancangan Sistem Informasi Penerimaan Mahasiswa Baru. Jurnal Ilmiah ESAI Volume 6 No. 3 ISSN:1978-6034. 


\section{Biodata Penulis}

Arden Simeru. Lahir di Simawang pada 07 Agustus 1977. Menyelesaikan Pendidikan S1 di program studi Pendidikan Teknik Elektronika Universitas Negeri Padang. Dilanjutkan S2 pada Magister Ilmu Komputer UPI "YPTK" Padang. Saat ini bekerja sebagai Dosen di Sekolah Tinggi Teknologi Pekanbaru dan juga sebagai guru SMK Negeri 4 Pekanbaru.

Ambiyar Pendidikan S1 diselesaikan di prodi Pendidikan Teknik Mesin IKIP Padang.
Dilanjutkan Pendidikan S2 di program Magister Pendidikan Vokasi IKIP Yokyakarya. Dan Pendidikan S3 di program Doktor PTK Universitas Negeri Jakarta. Saat ini aktif sebagai dosen di Pascasarjana Universitas Negeri Padang.

Wakhinuddin, Pendidikan S1 diperoleh di Pendidikan Teknik Mesin IKIP Padang. Dilanjutkan S2 di Magister Pendidikan Vokasi IKIP Yokyakarya. Dan S3 pada program Doktor di PTK Universitas Negeri Jakarta. Saat ini aktif bekerja sebagai Dosen di program Pascasarjana Universitas Negeri Padang. 